\title{
Re-examining the fundamental principles of the NHS
}

\author{
J B L Howell
}

This is the first in a series of articles responding to the questions raised by the BMA's document, "Leading for Health." The document looks well beyond the coming British election and raises questions about health and health care that will be on the agenda of many countries into the next century.

Southampton General Hospital, Southampton SO9 4XY

J B L Howell, FRCP, professor of medicine

B.MF 1992;304:297-9
Leading for Health: a BMA Agenda for Health states that "progressively the high principles of the caring services have been eroded." While it is true that in recent years the ability of the NHS to keep pace with the ever increasing demands on it has been reduced, I see no evidence of erosion of the underlying principles as stated in the NHS Act 1946: "It shall be the duty of the Minister of Health ... to promote the establishment ... of a comprehensive health service designed to secure improvement in the physical and mental health of the people.... and the prevention, diagnosis and treatment of illness.... The services so provided shall be free of charge, except where any provision of the Act expressly provides for the making and recovery of charges." The act never promised that the NHS would be either all inclusive or totally free of charge.

A key word in the present context is "comprehensive," which is sometimes assumed to mean all inclusive; but the definition of comprehensive is "comprising much; of large content or scope." Clearly the NHS remains comprehensive within this definition; it never has provided nor ever could provide for every conceivable need. ${ }^{2}$

\section{Providing an adequate health service}

Has the range and quality of care in the NHS fallen below the public's expectation? Is care being denied to anyone who has a reasonable chance of benefit? Certainly this has sometimes occurred: some people wait excessively long times for treatment; a child in Birmingham could not get cardiac surgery until the secretary of state intervened; haemodialysis was rationed in the 1960s; organ transplantation is still limited. But in comparison with the totality of care provided by the NHS these deficiencies are few and far between. It is not the range of care that is limited, rather it is the length of time some people have to wait that is the problem. We cannot be satisfied with the present service, yet equally, concern that at any moment a decision may be made explicitly to reduce the range of care provided by the NHS is unjustified.

Concern about providing an adequate health service is not limited to the United Kingdom. Similar concerns are being felt worldwide, ranging from those countries that have so little national and individual income that they can support only the most rudimentary of health services to affluent countries such as the United States, which despite spending more than $12 \%$ of its considerable gross domestic product on health does not provide care for millions of its citizens. Public concern in the United States was recently expressed in a cover story of Time magazine which recommended changes to the systems of health care.

The question posed by the BMA therefore is timely: Can we maintain equal access to an NHS which provides a comprehensive, good quality service to all in need, largely free at the point of delivery? The question has been focused by the NHS Act 1990, which has made the work of the NHS more explicit than at any time previously.

\section{Can we afford a national health service?}

The ability of the NHS to meet its goals is certainly thought to be under threat because in recent years we have not been matching rising demand with corresponding additional resources and the gap between the two until recently has been widening. While we cannot control advances in medical knowledge and technology, we can influence the allocation of resources. A key question therefore is why more money is not being made available. Have we reached the limits of our ability to pay more for our health service? I think not. Between 1948 and 1980 expenditure on the NHS in England (and presumably in Wales and Scotland also) increased on average by about $4 \%$ per annum after correction for the effects of inflation (fig 1). This seems to have been sufficient to meet rising demands and to avoid major crises. Extrapolation of the best fit curve beyond 1980-1 shows the level of funding expected if the same rate of increase had continued. But in reality, starting in 1980-1 there was a striking reduction in the rate of increase in funding to about $1 \%$ per annum and the gap between expectation and allocation rapidly widened. This lower rate continued for several years, during which time health authorities were required to make cash savings and cost improvements while still coping with ever increasing demands for health care. Clearly this could not continue indefinitely and after a few years, as problems became more widespread, the rate of funding was increased (fig 2).

Because the economic fortunes of the United Kingdom over this period did not change abruptly the reduction in the rate of increase in funding between 1981 and 1985 must have been a positive decision rather than one forced on us. What might have been the reasons?

Firstly, the reduction was consistent with the government's policy of limiting the growth of public expenditure. Secondly, there is the "bottomless pit" concept - that is, we will never be able to meet all of the needs of the health service no matter how much money we put into it; therefore we shouldn't try. Thirdly, doctors are sometimes perceived as being arrogant, self interested, and unaccountable and not the best advocates for increased resources. Fourthly, and most importantly, was the perception, until recently, that the resources already provided were not being used efficiently or effectively, that waste abounded, and that extra demands could be met by improvements in the way existing resources were used. 
FIG 1 (left) -Expenditure on NHS in England between 1948 and 1980 corrected to 1986 prices by annual retail price index. Best fit curve is extrapolated to show expenditure expected if annual rate of increase (4\% compound) had been maintained. Between 1980 and 1986 rate of increase slowed to about $1 \%$, with stippled area showing gap between expected and actual expenditure FIG 2 (right) - After 1986 rate of increase was increased substantially but gap of about $£ 0 \cdot 5$ bn per annum remained in 1990
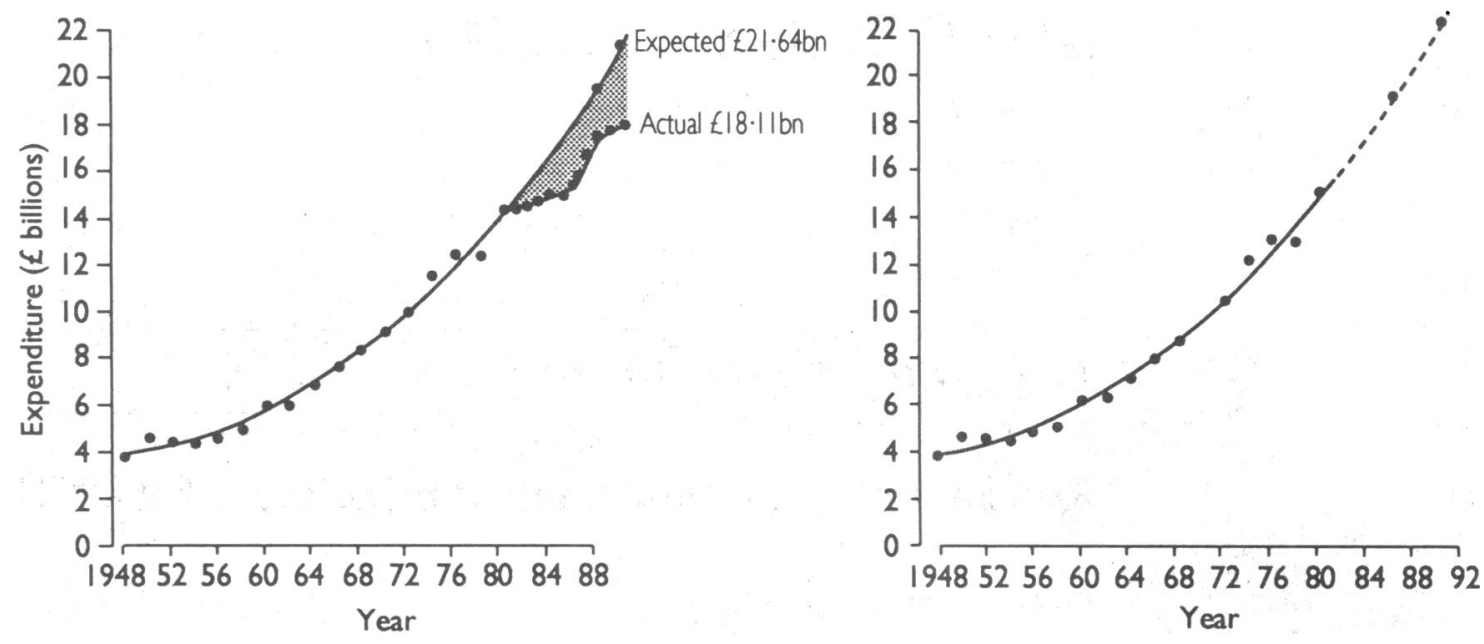

Efficiency and effectiveness in the NHS

There have been many changes designed to improve the efficiency of the NHS. There were two major reorganisations of structure in 1974 and again in 1982, but there is no evidence that they made any significant difference. Perhaps the biggest change in this respect occurred in 1983, when Sir Roy Griffiths was asked to review the management structures in the NHS. ${ }^{+} \mathrm{He}$ pointed out that consensus management, which had been introduced in the 1974 reorganisation, meant that no one individual was in charge of anything. His recommendation that general management should be substituted was immediately accepted and implemented.

There was one important omission from this constructive report: while Sir Roy described in some detail how general management should be applied to the provision of the resources to the users, it stopped short of recommending how it should be applied to the management of the use of the resources by the users, the clinicians. Sir Roy identified the importance of doctors being involved in management, but without any existing models to draw on widely did not attempt to recommend how this complex and sensitive process should be done. He did, however, focus attention on this deficiency and in the following year clinical directorate systems were introduced, first at Southampton General and Guy's Hospitals, and subsequently at many other hospitals. ${ }^{5}$ This development has been crucially important to the management of clinical resources of hospitals and to instil confidence that resources are being managed and efficiently used.

But despite all of these structural and managerial changes crises of funding continued to occur and led eventually to the prime ministerial review and the major reforms which are embodied in the NHS Act 1990. The essence of the reforms is the separation of the functions of purchasing health care (by health authorities) from the provision of care by providers (the acute hospitals, community units, etc), the two being linked by "contracts." This has shifted some of the power to prescribe how resources will be allocated from doctors (and nurses) in favour of managers and health authorities, and this is widely accepted. It is also recognised that only doctors and nurses acting as general managers can really manage the use of the resources. It is abundantly clear that the efficient running of the NHS requires a willing partnership between professional activity and management.

\section{"Consensus rationing"}

The NHS reforms are geared to better management, more accountability, and better value for money; there is nothing in them that implies explicit rationing of care, yet this is now a widely held fear. Why? Simply because many people seem to think that we cannot continue to provide additional resources to meet all reasonable health care needs. Support for this view has been lent by the recent controversial decision of the North East Thames Regional Health Authority explicitly to exclude five categories of treatment from their responsibilities. Further afield, the state of Oregon in affluent America has already introduced legislation to ration care explicitly by denying some categories of patients treatment under the largely state funded Medicaid programme. ${ }^{67}$ Further, some of our own health economists are promoting quality adjusted life years (QALYs) as a basis for allocating resources to the more cost effective procedures, and, by implication, high cost and low QALY procedures should not be funded if resources are limited.

One advantage of this form of "consensus rationing" is that it removes from the individual doctor the possibility of conflict with his or her fundamental ethical responsibility of making decisions only in the interests of the patient once he or she has accepted responsibility for the patient's care; this is implicit in the Hippocratic oath. He or she does not have to worry whether the cost:benefit ratio is good enough-the community has already taken this decision and the doctor-patient relationship has not been directly compromised.

But can a community come to these decisions with a clear conscience? Can it be confident that its decisions are just? The experience of Oregon is not encouraging. A process of cost-benefit assessment plus community consultation about the "value" of different treatments resulted in at least one major anomaly: cosmetic breast surgery was ranked higher than treating an open

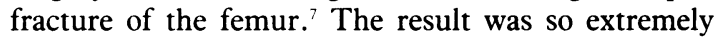
unreasonable that it was unacceptable, but less obvious anomalies would probably pass unchallenged. Assessments made on the basis of costs and benefits, which are poorly quantified, with the ratio then modulated by "value" judgments made by members of the public, do not inspire confidence. By contrast, at present health authorities make decisions about the allocation of resources to different categories of care; doctors decide about allocations to individual patients, taking into account their detailed personal and medical circumstances together with the pressures on local resources. As long as the gap between demand and resources is not wide, there is no inherent problem with this system. Doctors are given the final decision whether or not to treat within the resources available after balancing their two responsibilities, one to the patient and the other to the community. If treatment is not urgent patients may be placed on a waiting list. As long as this option is available the decision is then not whether to treat but when to treat. The size and nature of the waiting list becomes an important "error signal," 
reflecting the inadequacy of the service provided, and has the potential for influencing the political decision of the size of the allocation to health care. If resources do not match need the choice seems to lie between the "cost-benefit" list and the waiting list. I find the waiting list morally and practically the more acceptable; its power to gain more resources for the NHS has been well demonstrated.

But have we arrived at the stage where we should accept as inevitable the de facto rationing of the waiting list or the more explicit model of the Oregon experiment ${ }^{8}$ If we have not reached the limit of our ability to fund the increasing demands of the NHS the question we should be asking is not how are we going to ration care - that is, how are we going to rationalise denying some patients care, and in so doing destroy the fundamental principles of the NHS. Rather the question should be how can we ensure that an adequate proportion of the gross domestic product is devoted to the NHS to allow it to meet its responsibilities? Also, how can we ensure that what is already allocated to the NHS is used efficiently and effectively? This is exactly what the reforms are about. Now is surely not the time even to think about denying care to anyone. Anyone can solve the problems in this way; the challenge is how to maintain our commitment to the principles of a comprehensive health service when resources are not plentiful and demands are constantly rising.

\section{The way ahead}

Before the reforms the structure of the NHS did not ensure accountability and give confidence to those responsible for allocating the nation's resources that the service was being or ever could be run efficiently and effectively. The new structure has the potential for doing so and it is in everyone's interests that it succeeds. This requires that doctors and everyone else in the service do their best to make it work.

An important new requirement of the NHS Act 1990 is that the needs of each community shall be assessed and published annually in the Director of Public Health's report. Health authorities, as purchasers, are contracting provider units - for example, acute hospitals, community units-to provide specified quantities and quality of care, and this is monitored. It will soon become apparent what needs are not being met, and the public will be able to judge whether or not it is satisfied with the level ${ }^{1}$ and deployment of funding of their NHS. Once it is clear that more care cannot come from greater efficiency and effectiveness, the only argument against providing more money is that none is available. Who can assert this today when the United Kingdom spends less on health than most countries in the Organisation for Economic Cooperation and Development, our expenditure per capita being on a par with that of the poorer "olive" countries of Europe.

There is no need even to entertain the possibility of denying explicitly defined groups of NHS patients reasonable care in 1992 or the years immediately ahead. The time to consider the approach introduced by the North East Thames Regional Health Authority and by Oregon is when we truly cannot afford to pay for the quality and range of care that we want - but that time is not yet here. We have not reached that point in the NHS after 42 years of remarkable medical advances - personally, I doubt that we ever shall.

1 BMA. Leading for health: a BMA agenda for health. London: BMA, 1991 2 Thwaites B. The NHS: the end of the rainbow. Southampton: Institute of Health Policy Studies, 1987

3 Condition critical. Time 1991 Nov 25:34-42.

4 NHS Management Inquiry. Report. London: DHSS, 1983. (Griffiths report.)

5 BMA. CCSC guidance on clinical directorates. London: BMA, 1990.

6 Dixon J, Welch HG. Priority setting: lessons from Oregon. Lancet 1991;337: 891-4.

7 Klein R. On the Oregon trail: rationing health care. BMf 1991;302:1-2.

8 Smith R. Rationing: the search for sunlight. BMf 1991;303:1561-2.
British Medical Journal, London WC1H 9JR Fiona Godlee, MRCP, assistant editor

BMF 1992;304:299-304

\section{Health and the Environment}

\section{Environmental radiation: a cause for concern?}

\section{Fiona Godlee}

Radiation is an obvious focus for public concern. It is known to cause cancer and inspires anxiety becauseunlike that other widely available carcinogen, cigarette smoke-it is beyond the individual's control. But is there evidence that radiation at levels encountered in the environment is dangerous to health?

\section{Sources of radiation}

Ionising radiation has always been part of our natural environment, being emitted from the earth's core and the solar system (box). It is only in the past few centuries that man has added to natural background radiation: underground mining has led to exposure from radioactive rocks; air and space travel have taken people closer to the sources of cosmic radiation; modern building technology has contributed to the accumulation of the radioactive gas radon in homes; and the discovery of $x$ rays has spawned a whole industry of diagnostic and therapeutic radiology. ${ }^{1}$

The National Radiological Protection Board estimates that the average person in Britain receives a dose of radiation of $2.5 \mathrm{mSv}$ each year. Of this, $87 \%$ comes from natural sources-over half from radon decay products in the home. Medical radiation contributes $12 \%$. All other artificial sources-nuclear fall out, occupational exposure, and discharges from nuclear installations - account for about $1 \%$ of the total amount (fig 1).

The discovery of high levels of radon in homes in some areas of Britain has given the nuclear industry a chance to put its own contribution to environmental radiation into perspective and diverted public attention away from nuclear installations. But radon is a natural

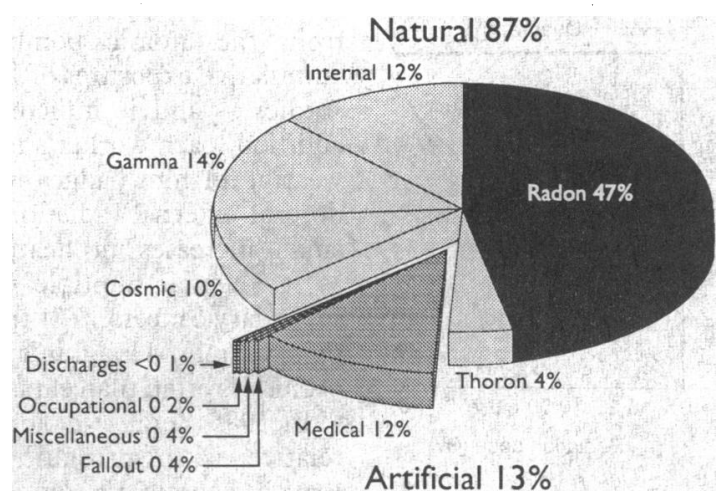

FIG 1 -Contribution of different sources of radiation to annual average dose 